\title{
Ethiopia's Manufacturing Industry Opportunities, Challenges and Way Forward: A Sectoral Overview
}

\author{
Tekeba Eshetie* \\ Ethiopia Meat and Dairy Industry Development Institute, Ethiopia \\ *Corresponding author: Tekeba Eshetie, Ethiopia Meat and Dairy Industry Development Institute, Bishoftu, Ethiopia
}

Submission: May 02, 2018; Published: May 23, 2018

\begin{abstract}
The growth of the manufacturing sector within industry is essential to build national technological capacity, industrial capability and create broad based job opportunity and improve income. In addition to this, the development of the manufacturing industry helps to improve the total factor productivity and competitiveness of the overall economy and its trickledown effect to up and down the supply chain. Because of existence of a number of comparative advantages in the country and to strengthen its competitiveness the Government of Ethiopia offered multiple incentives for the growth of the manufacturing sector. Though the manufacturing sector is a way out for sustainable economic development its growth is not without challenges. The major ones include unskilled labor forces with limited experience; limited infrastructure; external pressure from global market, shallow industrial research and development activities, underdeveloped market information system, problems related to trade logistics and limited promotion made on the resources and other opportunities. So, this study is therefore proposed to develop recommendations based on the national and international experiences and identification of the pros and cons of the manufacturing sector in Ethiopia and other developing countries. The study seeks to propose some intervention measures so as to alleviate these challenges which include but not limited to entrepreneurial, managerial and technical skill development together with the introduction of the philosophy of kaizen; establishment of plug-and-play integrated agro-industrial parks to address multiple constraints; alleviate trade logistics by regional integration along key business corridors by improving connectivity through development of hard infrastructures like multimodal trucking system; railways, airways and shipping. Simplify custom procedures and leverage information and technology capacity building; strengthening industrial input supply system; expedite the development and promotion of lease financing and evaluation of the government incentive mechanisms.
\end{abstract}

Keywords: Competitiveness; Growth and transformation plan; GDP; Manufacturing; Trickledown effect

\section{Introduction}

Ethiopia has experienced rapid economic growth since 2005 with real Gross Domestic Products (GDP) growth rate of 10.5 percent per annum compared to 5 percent for Sub-Saharan Africa between 2005 to 2014 [1-5]. This sustained double-digit economic growth has been instrumental in lifting millions out of poverty and increasing the productivity of the households across the country this is the best demonstration of the Ethiopian government commitment of spending $70 \%$ of the national expenditure on pro-poor sectors [5,6]. From 2000 to 2011 the well being of the Ethiopian households improved on several dimensions [7]. This rapid economic growth has enabled significant reductions in poverty from 39 percent in 2005 to below 22 percent in 2015 [7].

According to Hana [6], Ethiopia has now become the $7^{\text {th }}$ biggest economy in Africa and the $69^{\text {th }}$ in the world with 118.2 Billion USD GDP purchasing power parity for 2013. That is over 9 billion USD growths from the previous year and was hailed as a remarkable annual growth particularly for an economy without oil, gas or any significant minerals and much ahead of many notable countries with oil.
Sector wise, agriculture which is the main stay of the economy grew by 6.6 percent while industry and services expanded by 20.2 and 10.8 percent, respectively revealing the fact that the economic growth in Ethiopia has turned to become broad based [8,9]. The percentage share of GDP by major economic sector in the year 2010/11 was 44.7 for agriculture, 10.5 for industry and 45.5 for the service sector but these figures changed to $38.5,15.1$ and $46.3 \%$ in the year 2014/15 in the same order of the sectors $[9,10]$.

According to the Ethiopia National Planning Commission Report and Business Landscape [9,11], for sustainable growth and development of the economy, structural transformation from low-productive agriculture and informal sector to high-productive industry sector is a must. According to Narasimha and Ramesh [12], manufacturing is the engine of economic growth and structural transformation. According to these authors, Ethiopia is one of the few African countries that have formulated and implemented a fullfledged industrial development strategy since early 2000s when industrial policy had been a taboo in the international policy forums. The growth of the manufacturing sector within industry is essential 
to build national technological capacity, industrial capability, technology progress, productivity and capital accumulation [13-16]. Transfer of surplus resources from agriculture to manufacturing, economies of scale and positive spillovers effects and create broad based job opportunity and improve the total factor productivity and competitiveness of the overall economy are also the other advantages of manufacturing [13-16].

The Ethiopia National Planning Commission Report [9], further stated that, the focus of the second Growth and Transformation Plan is development of light and small manufacturing enterprises that are globally competent and leading in Africa that will establish a foundation for further growth of heavy industries that ultimately enable Ethiopia to become a middle-income economy by 2025 . Ethiopia has a comparative advantage in exporting textile and garments, leather and leather products, processed agricultural products as a result of its natural resource endowments $[17,18]$. But the manufacturing sector is underdeveloped in Ethiopia even by African standards with the exception of a few success stories in narrow areas such as leather and textiles and the sector is small and highly import dependent $[19,20]$. On top of this the CSA [21] second quarter report for the manufacturing sector indicated that, the share of manufacturing export from all manufacturing sales was only $3.8 \%$ where the rest of the balance is for local market. This implies that for export-led manufacturing industry growth to be realized, the focus should be on curving the binding constraints along the whole value chain instead of targeting only the upstream challenges. Therefore, this review study is initiated to explore the present status, future prospects and way forward of the manufacturing industries in Ethiopia with the following specific objectives.

A. Identifying major challenges and opportunities of the manufacturing sector in Ethiopia and to suggest some intervention measures.

B. To demonstrate the contribution of the manufacturing sector in the economic transformation process in Ethiopia.

\section{Manufacturing industry in East African Region}

It is widely acknowledged that a competitive and private sector-led manufacturing sector plays a key role in socio-economic transformation of the economy and development and development of the sector as a whole. It is also the heart and soul of many developed and developing country's economy and it has also the highest multiplier effect of any other sector [22,23]. In Africa, as a whole, the growth of the manufacturing sector was largely stateled, either via the nationalization of pre-existing firms owned by foreigners or via Greenfield investment in large, capital-intensive, state owned enterprises [24].

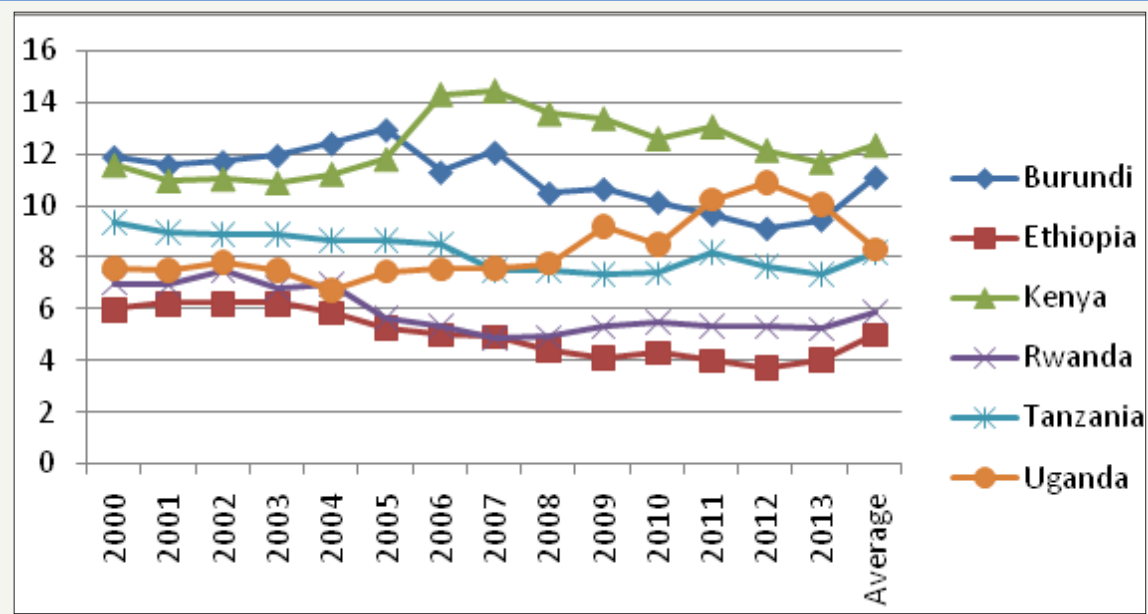

Figure 1: Manufacturing and its contribution for the growth of the GDP in some East African Countries.

Source: Rioba Evans M [26].

However, the manufacturing sector in Eastern Africa, is not as to the demand and its contribution to GDP (ranging from 3.8 to $11 \%$ ) and employment is small in the region, diversification is limited and the level of technological development is low, much of the activity still consists of minimal processing of agricultural and mineral sources $[25,26]$. On the other hand, quantitative and qualitative accounts of the manufacturing sectors and the policy context in Sub-Saharan Africa countries suggest there are now excellent experiences and opportunities in a range of manufacturing subsectors (garments and textiles, agro-processing, automobiles and consumer goods) countries such as Ethiopia, Kenya, Mozambique, Nigeria and Zambia [27]. The contribution of the manufacturing sector for GDP growth for some East African countries like Kenya and Uganda indicated that, there is a positive trend between 2000-2013 as presented in (Figure 1).

According to ADB [25], Manufacturing Value Added (MVA) per capita is highly desperate across East African countries. Kenya, which ranks second highest in the region in MVA per capita, registered strong growth in this indicator up to 2008, more than doubling from USD 39 in 2002 to USD 85 in 2008, but then experienced a decline with the crisis. Several countries in the region (Rwanda, Tanzania and Uganda) have managed to sustain relatively strong growth in this indicator since the mid-2000s from very low levels, while Burundi and Ethiopia have lagging behind. Not only 
are the trends divergent but also the levels are highly desperate, ranging from below USD 20 in Ethiopia to a figure some 75 times higher in the Seychelles. This implies, Ethiopia should figure out and work on the binding constraints for the sector to meet its industrial development vision. The overall contribution of each sector to GDP growth is very low for selected East African countries as indicated in Figure 2. This figure indicated that, the contribution of the manufacturing sector for GDP growth between 2007 and 2014 is declining for all the countries mentioned except Uganda. But when we consider the contribution of the overall industries to GDP growth, Uganda is still in a declining state similar to Kenya and Burundi. On the other hand, the contribution of agriculture to GDP is declining for Ethiopia and Rwanda but for the rest of the countries it is the opposite.

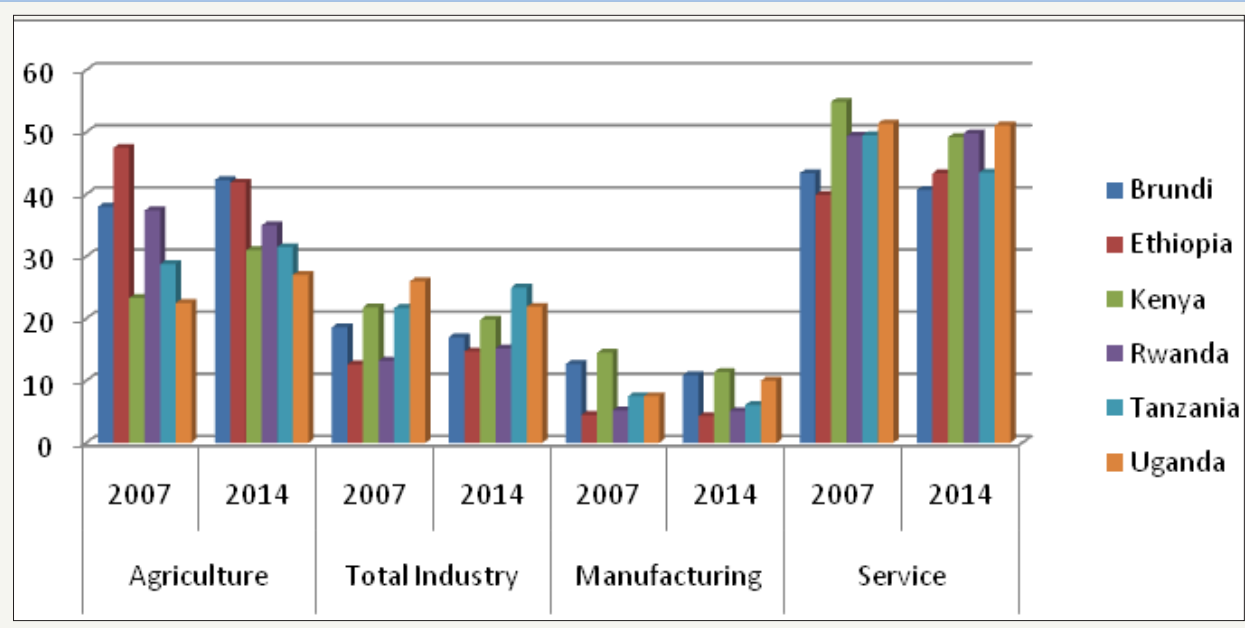

Figure 2: Structure of the economy share of the GDP in percent for selected East African Countries.

Source: From Ethiopia Economic Outlook Report [34].

\section{Production and Value Addition of the Manufacturing} Sector in Ethiopia

Gross value of production by manufacturing sector worth about 113 billion Birr in 2012/13 and value added generated is estimated to reach 32 billion Birr in the same year, which was about $4 \%$ of the value addition to the entire economy in the same year [25]. This report also indicated that, the largest value addition was come from the food and beverage subsector, which was around 8 billion Birr in 2012/13, followed by non-metallic mineral subsector (4.3 billion Birr) and metal and engineering subsector (3.9 billion Birr) while the smallest contribution came from textile and apparel industry (396 million Birr). The Ethiopian large and medium size manufacturing sector is dominated by food and beverages. It accounted for the largest proportion of the overall large and medium manufacturing value added between 2000/01 and 2010/11 [27]. However, according to this author, the valueadded share of the food and beverage industries declined by about 3.6 percentage points between 2000/01 and 2010/11.

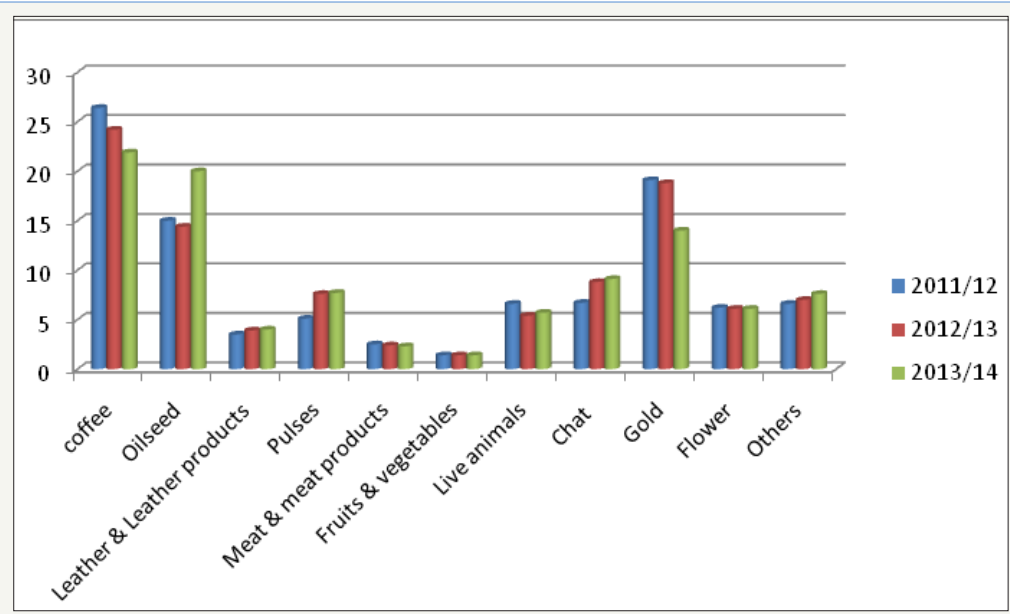

Figure 3: Percentage share of major export items in Ethiopia (\%).

Source: From CBE [1].

According to DAB [28], the manufacturing sector accounts for $70 \%$ of the industrial sector in Ethiopia. Within the manufacturing sector, the agro-processing subsector (food and beverage subsector) is the largest subsector, accounting for $36 \%$ of the total gross value 
of production (GVP) and 38\% of the value added [29,30]. The sector employs 60,110 people, both SMEs and publicly and privately owned larger companies. The strong linkages to the rest of the economy and the use of abundant agricultural products as inputs create a positive climate for the development of agribusiness in Ethiopia. The contribution of the major sectors to export findings including some manufacturing subsectors between 2011-2014 is indicated in Figure 3. The figure indicated that, Ethiopia is exporting more as primary products than value added products which in turn affect employment opportunity, better price and long term competency. As the graph indicated, the contribution of coffee, live animals and gold to export is in a decline state where as oilseeds, chat and pulses export is growing and meat and meat products and fruits and vegetables remain flat.

According to National Planning Commission Report [9], within the industry sector, medium and large scale manufacturing industries value added registered average growth rates of 19.2 $\%$ per annum and micro and small industries registered an average growth rate of $4.1 \%$ per annum during the first Growth and Transformation Plan period. The growth performance of the manufacturing industry which is the key indicator of the degree of structural transformation in the economy was lower than the target for the plan period. The poor growth performance of the micro and small scale manufacturing industries and delay in the implementation of large manufacturing projects were the major contributors to the slow growth in the overall manufacturing sector [31]. Therefore, proper implementation and consolidation of the micro and small scale enterprises development strategies is very important to unleash the potential of the sector in revitalizing local economic development, nurturing entrepreneurship and addressing unemployment and poverty. On the other hand, the National Planning Commission Report [9] indicated that, the major factor for low performance of the medium and large scale manufacturing sector in Ethiopia during the first growth and transformation plan is a short fall which is witnessed in attracting a large number of new and quality export oriented private investments in the manufacturing sector. The Ethiopian government believes that establishment of industrial zones and integrated agroindustrial parks can transform Ethiopian agricultural production from being fragmented and supply driven to becoming organized, safe, demand-led, quality oriented and means to address many of the challenges identified with respect to the development of the industrial sector UNIDO [30]. The trends of the contribution of the manufacturing export findings to the total export in Ethiopia is not consistent even declining after 2006 as indicated in Figure 4.

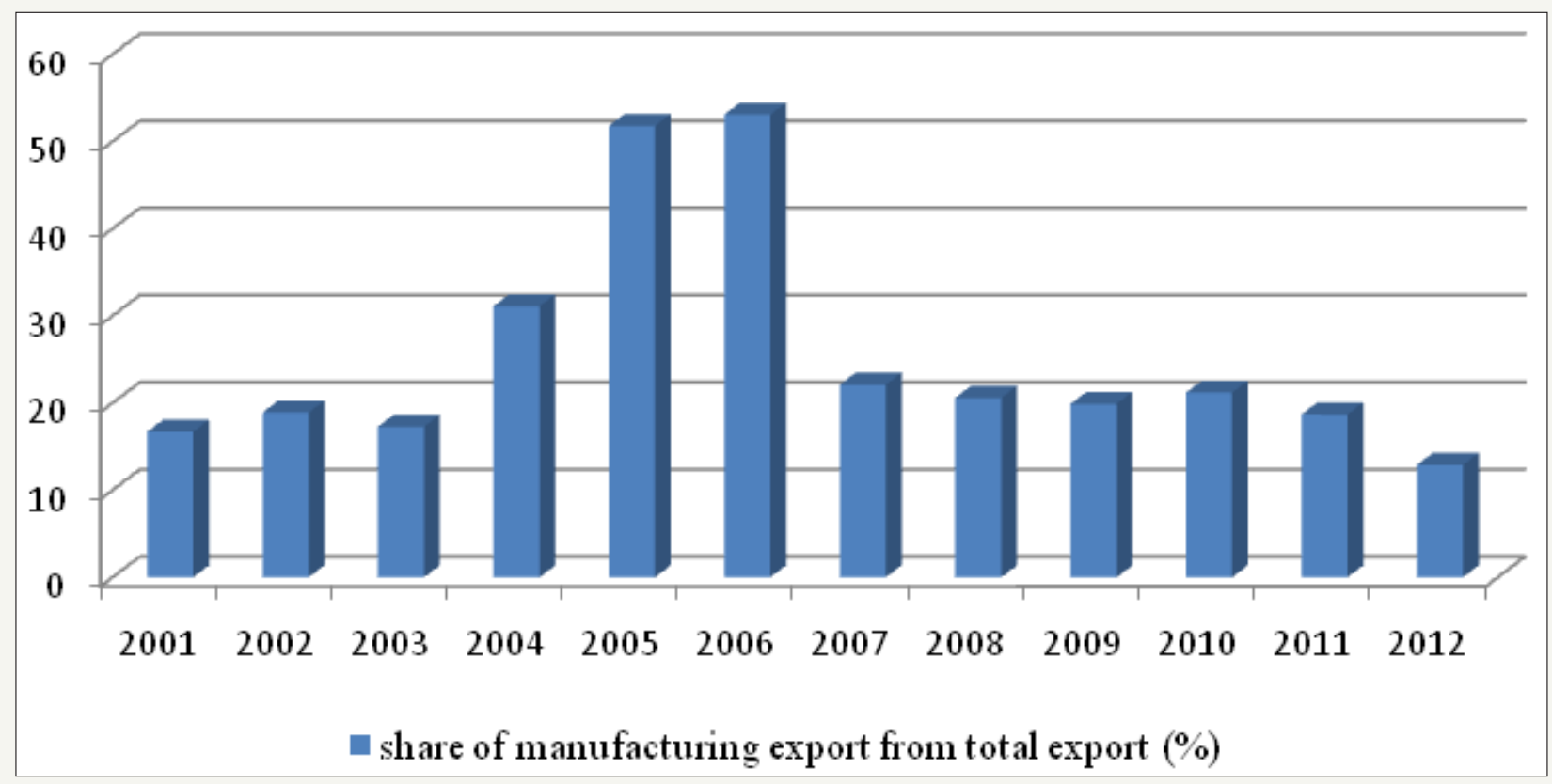

Figure 4: Share of the manufacturing export to total export of Ethiopia for the year 2001-2012.

Source: ADB [25].

The other major factor responsible for low performance of the manufacturing sector as per UNIDO [30] report is export products were of lower value added, while others were less diversified both in terms of products type and market destination. Still some other manufacturing exports were found to be very basic and of lower quality, fetching with lower prices and becoming more vulnerable to global economic shocks as well as bargaining power of the buyers. In addition to export-oriented industrial development strategy, significant emphasis was also given to promoting efficient import substitution industrialization; however the country is still dependent on foreign import as indicated in Figure 5 for meat sector which also applies to other imported livestock products. The unit price of a kilo of fresh beef exported from Ethiopia mainly to the Middle East countries is a maximum of 4 USD where as the importing price from South Africa for fresh beef it goes up to 10.33 USD which needs a study at the end market and the whole value chain. 

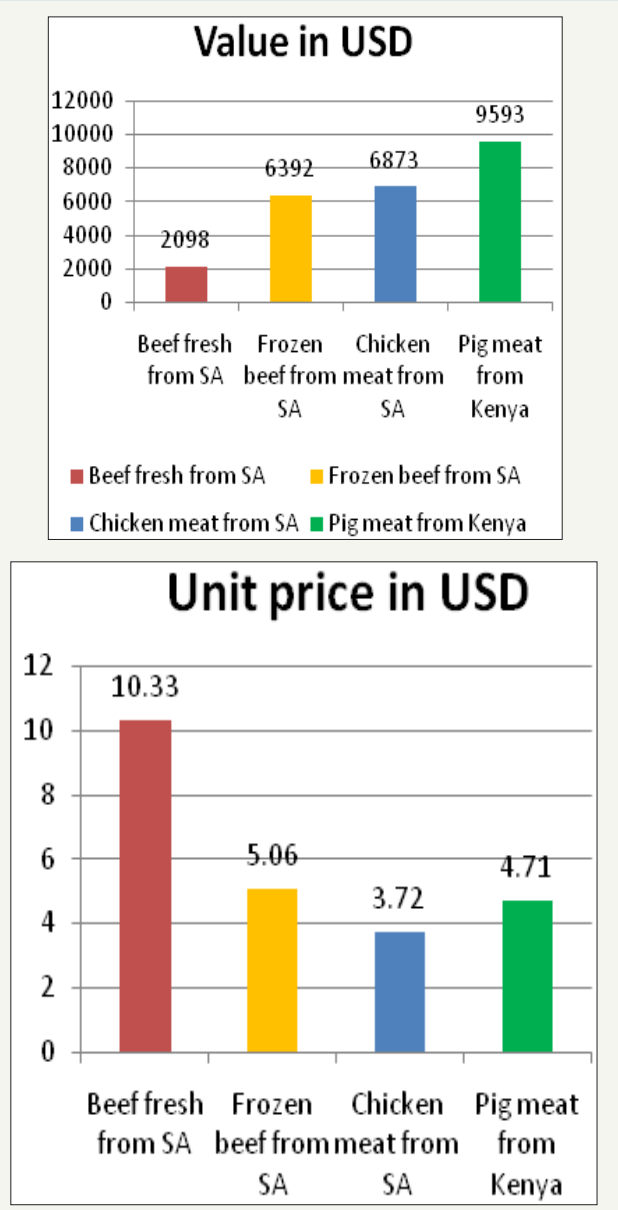

Figure 5: Import of different meat types from different countries to Ethiopia in 2006 (in USD).

Source: Compiled from Karl [35].

\section{Manufacturing and Job Creation in Ethiopia}

According to Tadele et al. [28], in Ethiopia the proportion of the employed population in the working age population has increased by 0.5 percentage points between 2005 and 2013. The sectoral structure of employment reveals that the share of employment in agriculture has declined significantly from 80.3 percent in 2005 to 72.7 percent in 2013 , declined by about 7.6 percentage points which indicated some sort of structural transformation. The service sector has assumed a great role in employment generation, where its employment share increased from 13.1 percent in 2005 to 19.9 percent in 2013.

Labor productivity growth in Ethiopian service sector is relatively high conversely, labor productivity growth in manufacturing sector is relatively low [7]. However, employment in large and medium manufacturing sector increased from 93,737 in 2000/01 to 173,397 in 2010/11, grew at an annual average rate of $6.3 \%$. Similarly, the number of manufacturing establishments also grew on average by $10.5 \%$ per year over the same period. Both manufacturing value added per employee and per establishment fell over the period as the number of establishments grew, indicating that large and medium manufacturing enterprises have become less labor intensive [28]. On the other hand, the employment share of private manufacturing industries in total manufacturing employment within large and medium-sized group increased from $41.9 \%$ in $2000 / 01$ to $73.9 \%$ in $2010 / 11$. On the contrary, the share of public manufacturing industries shrunk from $58.1 \%$ to $26.1 \%$ which indicated that public investment in the sector is increasing. The employment distribution of the different firm size within the manufacturing sector indicated that micro enterprises employ 138,951 (51\%); small enterprises employ 10,960 (3.9\%); medium enterprises employ 14, 757 (5.4\%) and large enterprises employ 108,226 (39.7\%) in 2007/08 alone [32].

\section{Opportunities for the Manufacturing Sector in Ethiopia}

A. Private sector friendly government

B. Relatively cheap electricity charge in comparison to other African countries

C. Macroeconomic stability and rapidly growing economy

D. Relatively cheap labor force and rapidly increasing number of trained employees

E. Access to wide market which include large domestic market, COMESA, AGOA, EBA opportunities and China market etc. 
F. Competitive incentive packages which include export incentives [33-35]

G. The coming into being of Integrated Agro-Industrial Parks which facilitate one stop shopping for all the services, to gain economies of scale, for bulk purchasing and selling, extension services, and development of common infrastructure [30]

H. The country has gotten a strong global attention due to its remarkable economic growth and credit worthiness

\section{Challenges of the Manufacturing Sector in Ethiopia}

A. High logistics and transportation cost

B. Limited study and action on export incentives

C. Low labor productivities

D. High cost of imported raw materials for the manufacturing

E. Limited compliance to the international requirements and market

F. Limited research on manufacturing industries including end market study

G. Underdeveloped rural infrastructure which limits the expansion of manufacturing industries to the potential areas

H. Weak supply chain integration

I. Low level of technology

J. Weak market institutions and information system

\section{Conclusion}

The Ethiopian economy has been growing on the average in double digits for more than 11 years and similarly, due to prudent fiscal and monetary policy measures, inflation has been brought down to single digits after being a threat for macroeconomic development for some years back. The country has now become the 7 th biggest economy in Africa and the $69^{\text {th }}$ in the world. Sector wise, Agriculture which is the main stay of the economy grew by 6.6 percent while industry and services expanded by 20.2 and 10.8 percent, respectively revealing the fact that the economic growth in Ethiopia has become broad based. Even though the country is blessed with natural resources, the manufacturing sector hasn't contributed more than 5 percent to GDP. This is mainly attributed to low productivity of labor force including entrepreneurial and managerial skills limitations, obsolete technologies used, limited infrastructure development including trade logistics, limited access to finance, insignificant research and development work done so far to the sector, poor institutional framework and poor market information system.

\section{Recommendations}

Even though the manufacturing sector in Ethiopia is at its infant stage, it has been contributing a lot to economic growth and the transformation process. To leverage its comparative advantage as compared to its regional peers, the following recommendations are made to accelerate its growth. a. The need for properly benchmarking of the manufacturing sector from the East Asian tiger economies and improve access to finance both foreign and local currency specially for those industries involved in priority sectors, including export.

b. The introduction of and lease financing for the new investment.

c. Access to marketinformation systems through networking of firms to make them competitive in global as well as national markets.

d. Alleviate trade logistics by regional integration along key business corridors.

e. Entrepreneurial, managerial and technical skill development.

f. The introduction of the philosophy of kaizen in the manufacturing sector.

g. Establishment of plug-and-play integrated agro-industrial parks.

h. Leverage Foreign Direct Investment and encourage local investment and also promote infrastructure development in rural areas to expand the manufacturing sector.

i. Trigger investment in labor intensive manufacturing sector for the rapidly growing skilled work force in the country.

\section{References}

1. CBE (Commercial Bank of Ethiopia) (2014) Commercial bank of Ethiopia annual report.

2. Admit ZW (2015) Ethiopia.

3. EEA (Ethiopian Economics Association) (2015) The demographic dividend: An opportunity for Ethiopia's transformation.

4. Yared S, Alemayehu S, Seid N (2015) Ethiopia-an agrarian economy in transition. WIDER Working paper, 2015/154.

5. Yared S, Alemayehu S, Seid N (2016) Understanding the African lionsgrowth traps and opportunities in six dominant African economies.

6. Hana (2014) The rise and rise of Ethiopia. Tigrai Online.

7. Ethiopia's Great Run (2014) The growth acceleration and how to pace it. World Bank Group.

8. Seid NA (2015) Prospects and challenges of structural transformation in Ethiopia. Ethiopian Economics Association, Ethiopian Economic Policy Research Institute, Addis Ababa, Ethiopia.

9. National Planning Commission (2016) Growth and Transformation Plan II (2015/16-2019/20). Federal democratic republic of Ethiopia.

10. IMF (International Monetary Fund) (2014) The federal democratic republic of Ethiopia, selected issue paper. IMF Country Report no. $14 / 304$.

11. Business Landscape (2013) Invest in Ethiopia. The emerging workshop of Africa.

12. Narasimha M, Ramesh S (2015) Enhancing Ethiopian industrial growth by original equipment manufacturing. Journal of Multidisciplinary Engineering Science Studies 1(1): 1-8.

13. McKinsey Global Institute (2012) Manufacturing the future: The next era of global growth and innovation. New York, USA. 
14. Hinh TD (2013) Light manufacturing in Africa. Findings and Policy Lessons. World Bank.

15. UNIDO (United Nation Industrial Development Organization) (2015) Integrated agro-industrial parks in Ethiopia (IAIP).

16. UNIDO (United Nation Industrial Development Organization) (2014) Development of manufacturing industries in Nepal current state and future challenges.

17. Tsegaye T (2011) The idea of industrialization in Ethiopia: Fundamental issues for debate.

18. Kefyalew A, Tarkegne A (2013) Meat and live animal export in Ethiopia: Status, challenges and opportunities. Global Advanced Research Journal of Food Science and Technology 2(4): 54-59.

19. Peter M, Lamin B (2010) Ethiopia's economic growth performance: current situation and challenges. The African Development Bank Group Chief Economist Complex 1(5): 1-5.

20. Henok A, Derk B, Dan C (2013) Ethiopia's investment prospects: A sectoral overview. African Review of Economics and Finance 4(2): 203246.

21. CSA (Central Statistical Agency) (2016) Report on the $2^{\text {nd }}$ quarter of the 2016 manufacturing business survey. Addis Ababa, Ethiopia.

22. Teshome A (2014) Impact of manufacturing sector on Economic growth in Ethiopia: A Kaldorian Approach. Journal of Business Economics and Management Science 1(1): 1-8.

23. Rama MR, Simon ZT (2015) Performance measurement of manufacturing industries in Ethiopia-An analytical study. Journal of Poverty, Investment and Development (7).

24. Yaw A, Margaret, Mcmillilan, Jone P, Dirk W (2016) Promoting manufacturing in Africa. Supporting Economic Transformation. African Transformation Forum, Kigali, Rwanda.

25. ADB (African Development Bank), Regional Synthesis Report (2014)
East Africa's manufacturing sector, promoting technology, innovation, productivity and linkages. 50 years servicing Africa (1964-2014).

26. Rioba EM (2015) Manufacturing industry and economic development in Eastern Africa: A test of Kaldor's first Law. SSRN pp. 1-22.

27. Neil B, Stephen G, Jane K, Hope M, Dirk W, et al. (2016) Developing export-based manufacturing in Sub-saharan Africa. Supporting Economic Transformation.

28. DAB Development Research and Training PLC (2015) An overview of Ethiopian manufacturing sector. Addis Ababa Chamber of Commerce and Sectoral Association, Addis Ababa, Ethiopia.

29. Tadele F, Shiferaw K (2015) Economic growth and employment patterns, dominant sector, and firm profiles in Ethiopia: Opportunities, challenges and prospects. Swiss Programme for Research on Global Issues for Development, R4D working paper.

30.CSA (Central Statistical Agency) (2014) Ethiopia-statistical abstract-2013/14. Addis Ababa, Ethiopia.

31. Yodit G (2015) Assessment of the challenges of micro and small scale enterprises to contribute to sustainable development: the case of manufacturing enterprises in Addis Ababa. Master's Thesis, Addis Ababa, Ethiopia.

32. Mulu G (2013) Industrial policy and development in Ethiopia: Evolution and current performance. Learning to compete (L2C): Accelerating Industrial Development in Africa, conference organized by UNU-WIDER, Finland.

33. Ethiopian Investment Guide (2014) Ethiopia; A preferred location for foreign direct investment in Africa.

34. Ethiopia Economic Outlook Report (2016) The story behind numbers.

35. Karl MR (2009) What can Africa contribute to global meat demand? Opportunities and constraints. Outlook on Agriculture 38(3): 223-233.
Creative Commons Attribution 4.0 International License

For possible submissions Click Here

\section{Submit Article}

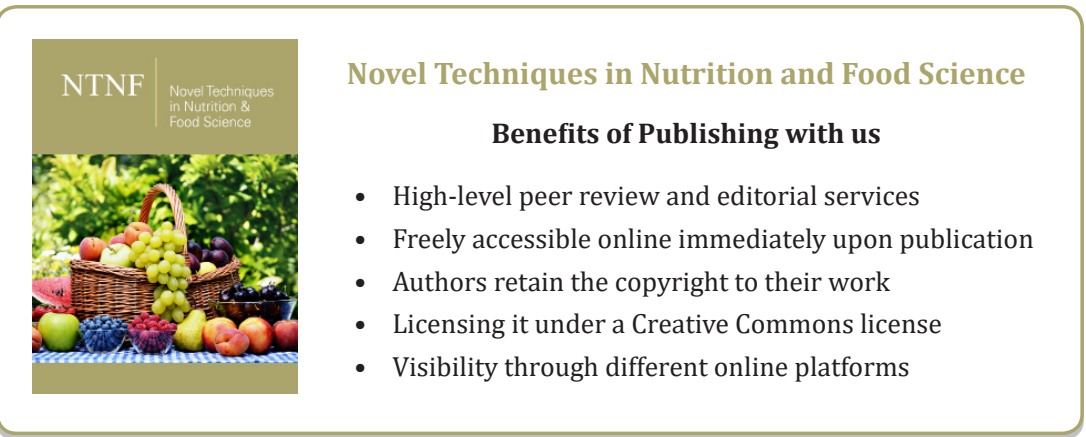

